\title{
Development of water supply systems in small municipalities
}

\author{
Vitaly Smirnov ${ }^{1, *}$, Valentina Pomogaeva ${ }^{2}$ and Dmitriy Shlychkov ${ }^{3}$ \\ ${ }^{1}$ Moscow Aviation Institute, Volokolamskoe highway, 4, Moscow, 125993, Russia \\ ${ }^{2}$ Voronezh State Technical University, Moscow Avenue, 14, Voronezh, 394026, Russia \\ ${ }^{3}$ Joint stock company «Mosgaz», 1/11, Mruzovsky lane, Moscow, 105120, Russia
}

\begin{abstract}
Supplying population of small municipalities with drinking water brings up a number of problems. The main ones are water production, its treatment and transportation. Studying the difficulties of supplying population with drinking water makes it possible to identify acute problems and to outline the prospects for the development of water supply systems. The statistical data on water supply problems are given. The dynamics of aging water systems is presented. Various water supply schemes are considered. There are highlighted unique details of each water supply system, that require an individual approach, careful preparation and analysis of the initial data, and performance of quite complex technical and economic calculations. The options for combining existing systems and their reconstruction are discussed. Water supply systems with a water tower are analyzed. Ways out of the crisis in water supply field are suggested.
\end{abstract}

\section{Introduction}

The term "small municipalities" in this article stands for towns and urban-type settlements with a population of up to 50 thousand people. It also includes rural settlements (villages) of more than a thousand population.

According to the Ministry of Natural Resources and the State Committee for Construction, Architectural and Housing Policy of the Russian Federation, there are 1097 cities, 1836 urban-type settlements and 24464 rural settlements in Russia with a total of "12323 municipal and 50794 departmental water supply systems" [1]. Urban population mainly receives water from surface sources and makes up $68 \%$, whereas population of towns and rural settlements usually use underground sources what is $32 \%$ of tap water.

116 million Russian citizens have access to running water $(78.97 \%)$ and 91 million - to water disposal $(61.95 \%)$. Therefore, 30.9 million people are not connected to centralized water supply system and 55.9 million - to centralized sewerage system. The total length of supply lines is 763 thousand $\mathrm{km}$.

$99.6 \%$ of cities and $88 \%$ of urban-type settlements are equipped with centralized water supply systems. As for 133.6 thousand rural settlements, the centralized water supply system covers about $22 \%$ of the total. There are 73 thousand rural settlements with a

*Corresponding author: svgvgy@mail.ru 
population of 25.4 million people, who have the running water. This is $64.8 \%$ of the rural population of Russia. Most water supply systems do not have the necessary facilities and technological equipment to improve the quality of water or work inefficiently. However, $65 \%$ of local water supply networks require reconstruction and more than $10 \%$ of them need to be fully restored. As a result, $75 \%$ of the rural population is forced to use water that does not meet sanitary standards. The main part of the rural housing stock is not fitted with utilities, for instance, tap water is available in $39 \%$ of rural residential buildings, sewerage in $30 \%$, central heating - in $37 \%$, hot water supply - in $17 \%$ [2].

The average capacity of water treatment plants reached 100 thousand $\mathrm{m}^{3} /$ day, in small towns and villages - about 19-22 thousand $\mathrm{m}^{3} /$ day, when regional centers rapidly developed in the 70-80s. Water treatment plants were built in small and medium-sized cities that previously did not have these facilities, Nevertheless, only $10 \%$ of them had water supply systems, the facilities of which in terms of productivity and technical equipment met the requirements of reliable and uninterrupted water supply to the population with its standard quality. By $199199 \%$ of cities and $86 \%$ of small settlements were fitted with centralized water supply. The average level of water consumption, taking into account industrial costs, reached 327 liters per day per person for household drinking and household needs.

In 2000 according to the Russian Association of Water Supply and Water Disposal, the deterioration of water supply networks was about $75 \%$ with fluctuations from $56 \%$ to $92 \%$, whereas it reached $70 \%$ of sewerage systems [2]. Reconstruction works of water supply networks, with building new supply lines, was $0.7 \%$ of the total length, and $0.4 \%$ of sewerage facilities, when a standard was $5 \%$ a year. The obsoleting of the networks for this period amounted to $21.5 \%$ for water supply, and $23 \%$ for water disposal. Leakage and unaccounted water consumption exceeded $30 \%$ of the supplied volume in $28 \%$ of cities.

A significant part of waterworks and supply lines was in operation for more than 50 years almost in all settlements, what resulted in partial or complete destruction and ignorance of technological processes of water treatment.

At the present time, the situation has slightly improved as a result of the implementation of the "Clean Water 2011-2017" program, though the problem of water supply and sanitation remains acute. According to the Russian Association of Water Supply and Sanitation, the cost of electricity to produce and sell $1 \mathrm{~m}^{3}$ of water is $30 \%$ higher than the average European level of water consumption per person [3].

\section{Materials and methods}

Water supply of small municipalities with a total water consumption of $3.9 \mathrm{~km} 3$ / year is conducted mainly from underground sources, what is $88 \%$ of the total supplied volume, or 7.5 million $\mathrm{m} 3$ / day, when only $12 \%$ ( 1.3 million $\mathrm{m} 3$ / day) is accounted for by surface ones. Problems of development and the unsatisfactory condition of water supply and sanitation systems in towns and rural settlements are due to their certain spontaneous growth and lack of attention to their efficiency and the quality of the supplied water.

Generally, additional water wells were drilled near the expansion zone, which were connected to the existing water supply network (Fig. 1, pos. 2, 3, 4) So, a centralized water supply system with decentralized power sources was created, when one or a group of wells provided a certain area with water. This network configuration has a number of advantages: transit flows are minimized, minimum diameters of water supply pipes are used, construction costs are cut, the opportunity of a phased development of the entire water supply system is provided. However, this significantly reduces the reliability of the system. For instance, in case of a failure of one or a group of local wells, the supply of water from adjacent zones is almost impossible due to insufficient pressure and low diameters of main 
lines. This plays a significant role for areas with varied landscape. As a result of such construction in small municipalities, an imperfect from a hydraulic point of view system of water supply pipelines, which usually have a diameter of 150-200 mm, was formed, when up to 10 or more single wells and water towers, scattered around the settlement, were connected to that network (Fig. 1).

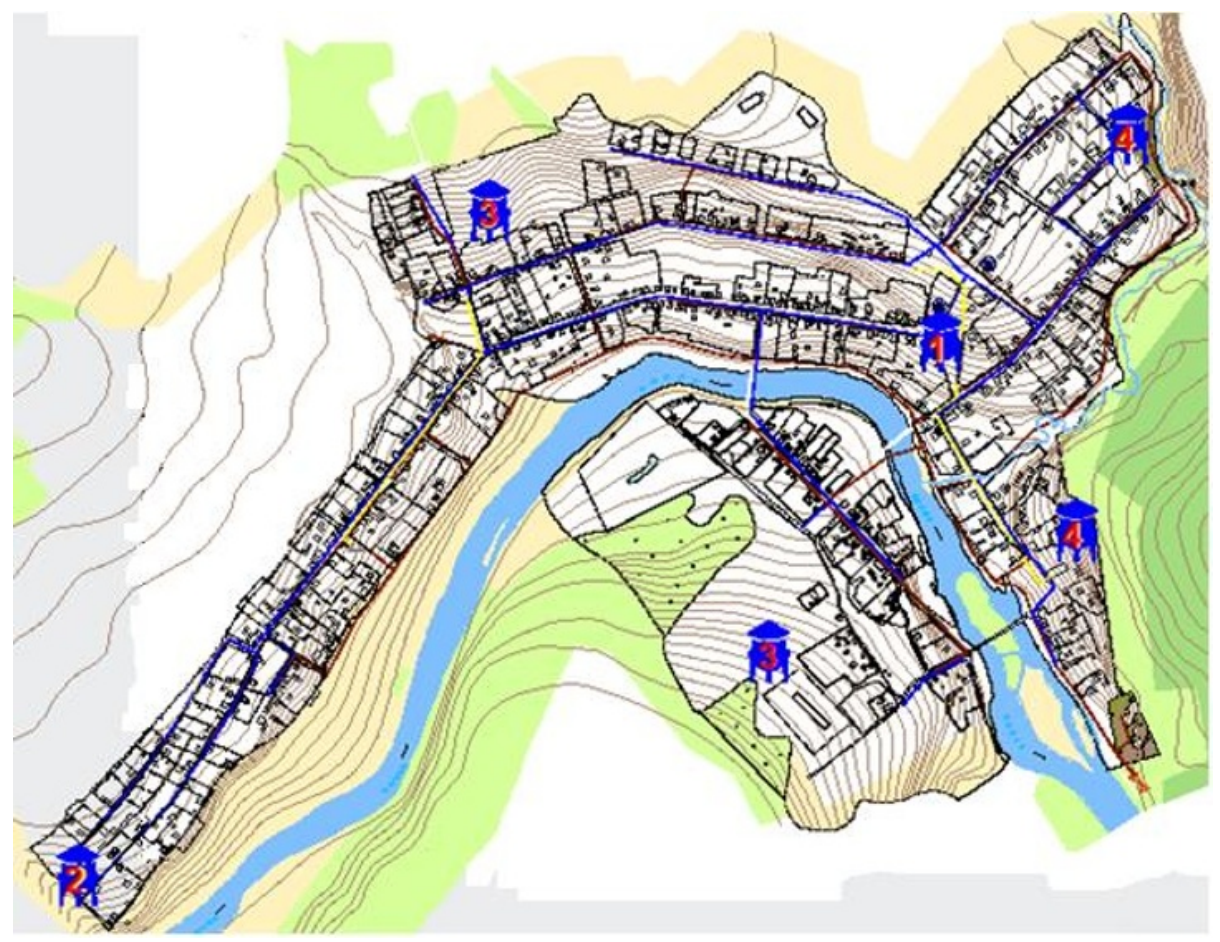

Fig. 1. Plan of construction and organization of water intakes in a small municipality.

Fig. 1 shows the stages of a settlement development [4], as it expands. In this example, all networks are connected and looped, which is a good version of the water supply system. In practice, "zonal water supply" is very common: one or two wells and a water tower supply water only to a certain zone. When connecting such networks, an imperfect hydraulic system arises that does not provide consumers with water in the required volume.

One of the reasons for the lack of water in the network is a big difference in pipe diameters, as a consequence, normal flow distribution is not met: some rings supply network are overloaded, when others are underloaded. The minimum pressure of the water supply network at the maximum drinking water intake at the entrance to the building should be at least $10 \mathrm{~m}$, but when constructing high-rise buildings in populated areas, this pressure is not enough to provide people with water [5]. Data on the growth of water consumption indicate that the performance of artesian wells is insufficient to meet people's needs fully. An important role in the water supply is played by frequent damage to the water network, both supply (external) and distribution (internal). Leaks range from $4 \%$ to $30 \%$ of the total water consumption due to its large wear and tear.

When constructing water supply systems in small towns and rural settlements, little attention was paid to the quality of the water. In addition, ground waters often contain iron concentrations in excess of established standards, as well as significant excess of standards for manganese, hydrogen sulfide, ammonium, oxidation, color and a number of other parameters. Outdated water treatment technologies, that are run in small municipalities, do not allow to achieve compliance of water quality with the Sanitary Regulations and Norms 
[6]. This adversely affects the health of the population. Condition of the supply networks is close to critical. The quality of drinking water is deteriorating. According to sanitary inspectors, $40 \%$ of the samples do not meet the standards, that is, $40 \%$ of the population drink poor-quality water. The organization of a centralized water intake with a treatment station becomes almost impossible without a radical reconstruction of the entire water supply network.

\section{Results}

When departmental water supply systems were handed over under municipal and private management without providing the necessary material, technical, monetary resources and production facilities, there was a deterioration in the level of technical operation of supply networks. The situation is aggravated by the fact that most of the water supply lines were built using the economic method without complying with the rules and standards. Reforming the housing and utilities complex, attracting modern management and large investments, that are necessary to upgrade and develop the infrastructure, does not always improve the state of water supply systems.

Thus, it is necessary not only to reanimate the rapidly collapsing sector, but also to change the organizational and legal affiliation, since the existing water supply scheme continues falling apart. When improving the water supply systems of small settlements, which use underground sources, a comprehensive solution of two main problems is required:

1. Improvement of the quality of drinking water by constructing water treatment facilities.

2. Optimization of the entire plumbing system in order to increase its hydraulic stability, reliability and efficiency.

An integrated approach is dictated by the fact that improving the quality of drinking water is possible with the construction of one centralized water treatment plant or multiple local stations at each well, what is technically and economically impractical, and sometimes almost impossible. In the first case, there is a need for a radical reconstruction of the water supply network in the conditions of the existing construction sector, the elimination of most existing wells and the construction of a centralized water intake. In the second case, it is construction of multiple water treatment stations with tanks and pumping stations of the second lift.

Analysis of the systems in a number of settlements has shown that it is more economically and technologically rational to create decentralized water intakes by building several group or local treatment plants. Until recently, such a decision was difficult to implement, since typical schemes required to build clean water tanks, a 2 nd lift pumping station with the installation of working and flushing pumps for the regeneration of filter loading and other auxiliary equipment. The implementation of such a bulky scheme on every single well is extremely economically inefficient.

Water supply system with a water tower, used for small settlements and enterprises, has several significant drawbacks. Except the high cost of the project, purchases, delivery and installation, it also requires a further maintenance. During the winter period, when there is a sudden temperature changes, with a decrease in water consumption, the overflow of water and its freezing on the walls can occur (Fig. 2), if the control system is out of order. These cases are frequently observed in the towers, that have been operating for long years. This leads to the destruction of the structure. Even during normal operation, a large oxidation surface happens when water fills the tower and then drains from it. That eventually leads to metal corrosion and further pollution of the water. Imperfect, from a hydraulic point of view, operation of the network and the water tower can lead to the stagnation of water, 
which can ripe for the development of various microorganisms. But the main drawback of the water towers under operation is their dilapidated, and often their emergency condition [7].

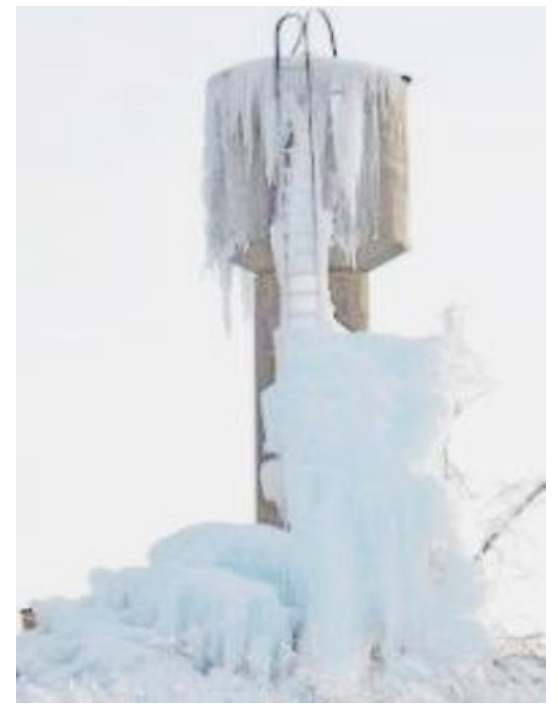

Fig. 2. Overflowed water tower in winter.

Nevertheless, water towers are an integral part of the water supply systems of small municipalities, especially for ones with a population of up to 5 thousand people. They contain not only the working volume for water consumption, but also, what is of vital, the fire prevention reserve, designed to extinguish a fire for three hours.

Bulky and expensive water tower of the Rozhnovsky type can be efficiently replaced with an automatic regulation of the pressure in the network through the use of a frequency converter and a pressure sensor. The use of equipment based on a frequency converter, which controls a well pump, cuts the expenses by more than 4 times, and in case of a tower reconstruction - by more than $30 \%$. Maintenance costs are reduced by $80 \%$. Energy and water savings range from 15 to 50\% [5]. The frequency converter provides for control of pressure in the pipeline from the well to the consumer by changing the speed of rotation of the pump. Working parameters are controlled automatically by means of a pressure sensor, which is installed on the pressure pipe. At the stop of water draw-off at night, the frequency converter smoothly stops the pump. The developed models of operational control of waterlifting wells and pipelines can reduce not only the cost of electricity, but also prevent accidents in the network [8]. The elimination of overpressure excludes pipeline rupture and, therefore, minimizes the leaks.

Hydraulic calculation is carried out at the design stage for the smooth operation of water supply networks. It sets the diameters, water head, network configuration and terrain. The diameters of the pipe sections are determined with an account of the normal and emergency distribution of flows, which leads to an overestimation of the design costs of main pipelines. Pipeline diameters are calculated for the peak hours, considering the water consumption for fire extinguishing, which, generally, significantly exceeds the maximum flow rate in small municipalities. As a result, the design diameters are much larger than it is needed. During the minimum load, water consumption is usually 10 times less than the designed one, which leads to a decrease in the speed of water flow and stagnation in the pipeline. The experience of hydraulic calculations for small settlements showed that water is renewed in the network on average in 2.5-3.5 days, that is, the network works as a 
pressure tank. According to the results of hydraulic calculations, the diameters could be narrowed up to $50 \mathrm{~mm}$, but this is impossible because of the need to use fire hydrants, which are installed on pipelines with a minimum diameter of $100 \mathrm{~mm}$ and a fire flow pass. Thus, a network is built with overestimated diameters and increased operating costs due to the supply of water under the pressure necessary for consumers.

The solution to this problem is possible with the installation of fire tanks and the provision of fire equipment for each small municipality (which cannot be optimized in today conditions). Extra fire pumps and construction of fire pump stations is also economically inefficient. Therefore, for the time being, integrated drinking-fire-fighting water supply systems operate in small settlements.

The water supply networks of small settlements are not always equipped with a water treatment system. When drawing water from underground sources, it may contain iron, manganese, hydrogen sulfide and other substances of exceeding and close to the maximum permissible concentrations. Outdated and partially destroyed water treatment facilities do not provide the population with quality and safe water. In some areas, it is possible to observe in the population a number of diseases because of water with certain elements (most often urolithiasis occurs).

The use of bulky water treatment systems for small settlements is impossible and not economically viable. The situation can be improved by compact water treatment plants designed for a small amount of water consumption. It is proposed to use methods for the removal of iron, manganese, hydrogen sulfide and other compounds, at water treatment plants in pressure, pressure-free and container design, that are made of metal with a reinforced polymer anti-corrosion coating or of structural, polymer materials. There are used a number of technological processes necessary to remove impurities (iron, manganese, carbon dioxide, hydrogen sulfide, chromaticity, etc.). The main ones are the processes of aeration, degassing, physicochemical or biological oxidation, filtering with the use of heavy loads. The use of reagent-free water treatment methods allows to automate the operation of such facilities. The parameters and combinations of structures are determined individually for each object; the composition and properties of the source water and local conditions define the ground. Water treatment mainly aims at the deferrization, demanganation, softening and disinfection with ultraviolet radiation or ozonation.

As an alternative option, it is possible to use individual water treatment systems for each house. The choice of a particular solution depends on many factors, the most important of which is financing.

\section{Discussion}

Providing the population with clean water is a priority for the long-term socio-economic development of the country. The solution of this problem will allow to improve the quality of life of people in small municiaplities, to prevent emergencies related to the operation of water supply systems and also to create conditions for the effective work of local organizations. The development and growth of production in related industrial sectors can be planned if the necessary materials and equipment for water supply system are fit up.

Since the necessary capital investments in the water supply sector cannot be made within one fiscal year and require significant expenditures of budgets of various levels, programs are being developed to improve housing and utility services. The program "Clean Water 2011-2017" was developed in order to improve the quality of water supply networks. As a result of its implementation, the situation in some localities became significantly better: new wells were drilled, water networks were shifted, water treatment stations were reconstructed. However, the problem of quality supply lines remains relevant. For the 
period until 2020, a program was adopted to improve the quality of water supply systems, in accordance with the Water Strategy Development of the Russian Federation.

The main objectives of its implementation are:

- elimination of the causes of inconsistencies in the quality of water supplied to the population with hygienic standards;

- differentiation of approaches to the choice of various technological designs of water treatment;

- Special approaching to the choice of schemes to supply drinking water in small municipalities.

The execution of the program will improve the quality of water supply systems, but the following economic factors and risks may affect its implementation:

1. Regulatory risks.

2. Macroeconomic risks.

3. Regional and municipal risks.

In order to reduce the impact of regulatory risks, it is necessary to constantly improve the regulatory and legal framework, governing the activities of organizations in the design, construction and operation of water supply systems. Delay in the adoption of planned legal acts may significantly reduce the efficiency of the Program.

Macroeconomic risks have an impact when the state of financial markets and business activity changes. This can significantly affect the cost of raised funds and lead to a reduction in the volume of investments in the water supply sector, a rise in the cost of equipment and materials.

Regional and municipal risks arise due to insufficient funding and limited budget, which is especially important for small settlements. With the implementation of measures for the modernization of water supply systems, the emergence of incomplete construction projects and facilities, which were put into operation without a full technological cycle of highquality water treatment, may arise. These problems occur due to the quality properties of water in the source and the scarcity of local budgets.

The cost of a liter of water in rural areas exceeds the same parameters in the city. This is related with operating costs and a small population. Such a water supply system cannot work well without additional subsidies.

In Russia, the capital expenditures for the restoration and reconstruction of water supply and sanitary systems make up only $11 \%$ of the operating expenses of organizations running them. In the world, this ratio is $74 \%$, that is, approximately $43 \%$ of the expenses of organizations are invested. This situation has arisen due to the managers in the public utilities system who do not understand the essence of the water supply and sanitary network. The goal of business managers (anti-crisis directors) is to maximize profits, with minimal investments. The infrastructure of water supply, water disposal and water treatment is rapidly dilapidating due to low capital investments. This leads to:

- breaks in the supply of water, due to the destruction of pipelines;

- degradation of the supplied water due to non-compliance with water treatment processes.

Deskilling and sometimes complete liquidation of enterprises or their transfer to a related sector, also negatively affects the supply of water to the population.

In the estimation of specialists, "tariffs for water supply, disposal and wastewater treatment services in Russia are about 3 times lower than in Western Europe. At the same time, the growth of tariffs in Russia is primarily due to the growth in operating expenses; thus, in the future the water bills in Russia will be comparable to ones in Western Europe, but with a significantly lower quality of services provided. Consequently, consumers pay repair costs, not renovation, which does not contribute to the improvement of the water quality. 


\section{Conclusion}

The features of each water supply system require a unique approach, careful preparation and analysis of the initial data, as well as performance of rather complex technical and economic calculations. The key factor is the composition and properties of the source water, as well as conditions of the area. This allows to optimally tackle the problem of treatment of even very complex groundwater. Priority methods are chemical-free water treatment methods. They are easy to automate and run. The result is minimization of capital and operating costs for the reconstruction of the water supply system due to its optimization by the criterion of energy consumption, reduction of the scope of work on the construction of new networks, tanks, wells and treatment plants.

On the basis of the research conducted, the following set of measures is proposed to modernize and develop the water supply system in small municipalities:

1. Reduction of specific water consumption in the residential sector.

2. Improvement of the quality of drinking water sources through the organization of water preserving zones and coastal bands.

3. Construction of local treatment facilities in conjunction with the development of sewerage system.

4. Improvement of the quality of drinking water through the introduction of modern technologies (modular treatment facilities, ozonation and membrane filtering).

5. Transition of chlorination water disinfection systems to sodium hypochlorite ones.

6. Development of a system to dispose industrial wastewater in order to reduce the negative impact on the environment through the construction of sludge dewatering shops.

7. Improvement of the reliability of the water distribution system, due to the reconstruction of the water supply network and its modernization.

8. Implementation of an integrated production process control system (joint operation of pipelines, pumping stations, control tanks, sewerage treatment plants).

\section{References}

1. I.Y. Purusova, V.V. Pomogaeva, Elektrotekhnicheskie kompleksy i sistemy upravleniya 1, 62-63 (2006)

2. V.I. Shcherbakov, I.Y. Purusova, V.V. Pomogaeva, Vestnik MGSU 12, 118-127 (2015)

3. V.V. Pomogaeva, Aktualnye napravleniya nauchnyh issledovanij XXI veka: teoriya i praktika 4-2 (9-2), 349-352 (2014)

4. V.V. Gluhov, I.V. Ilin, Lecture Notes in Computer Science 8638, 509- 518 (2014) doi10.1007/978-3-319-10353-2_46

5. I.V. Ilin, A.I. Levina, O.Yu. Iliashenko, MATEC Web of Conf. 86, 05028 (2016) doi 10.1051/matecconf/20168605028

6. S. Rinaldi, A Flammini, M. Pasetti, L. C. Tagliabue, A. C. Ciribini, S. Zanoni, 2018 IEEE International Instrumentation and Measurement Technology Conference (I2MTC), Houston, Texas, USA (2018). DOI: 10.1109/I2MTC.2018.8409740

7. V. Kankhva, IOP Conf. Series: Earth and Environmental Science 90, 012175 (2017) doi:10.1088/1755-1315/90/1/012175

8. I.G. Lukmanova, E.V. Nezhnikova, Fundamental research 10-8, 1791 (2016) 